\title{
The effect of amine substituent chain length on POSS/Polysulfone mixed matrix membrane
}

\author{
Y.C Bong ${ }^{1}$, P.C Oh ${ }^{* 1}$ and T.L Chew ${ }^{1}$ \\ ${ }^{1}$ Department of Chemical Engineering, Universiti Teknologi PETRONAS, \\ 32610, Seri Iskandar, Perak Darul Ridzuan, Malaysia \\ *Email: peiching.oh@utp.edu.my \\ Phone: +605-368 7568; Fax: +605-365676
}

\begin{abstract}
The main obstacle encountered during the development of polyhedral oligomeric silsesquioxane (POSS) mixed matrix membrane (MMM) via physical blending is the combination of compatible inorganic filler and polymeric matrix. In this work, mono-functional POSS of different amine functionalised substituent chain lengths namely aminopropylisobutyl POSS (AMPOSS-a) and aminoethylaminopropylisobutyl POSS (AMPOSS-b) were incorporated into Polysulfone (PSf) membrane at 1wt $\%, 2 \mathrm{wt} \%$ and $3 \mathrm{wt} \%$ loadings. The effect of amine substituent chain lengths on its compatibility and dispersion properties as well as the glass transition temperature of the MMMs were studied using scanning electron microscope (SEM), energy dispersive X-ray (EDX) and differential scanning calorimeter (DSC). Particle agglomerations were observed to increase with the loadings of both fillers although more prominent in AMPOSS-b/PSf membranes. This was attributed to the interparticle forces such as van der Waals and electrostatic forces. Distribution of both fillers were concentrated at the upper region of the membranes at $1 \mathrm{wt} \%$ and $2 \mathrm{wt} \%$ as a consequence of their density difference. The glass transition temperature $\left(\mathrm{T}_{\mathrm{g}}\right)$ for pristine $\mathrm{PSf}$ at $197^{\circ} \mathrm{C}$ showed an overall decrement between $40.3^{\circ} \mathrm{C}$ to $47.1^{\circ} \mathrm{C}$ when AMPOSS-a and AMPOSS-b were incorporated. The decrement was due to AMPOSS particle loadings, surface chemistry and particle-polymer chain topology. Hence, mono-substituted POSS with varying amine substituent chain lengths did not improve the glass transition temperature nor contribute to homogeneous MMM morphology. This had been identified to be the consequence of POSS surface energy, which might be caused by the association of hydrocarbon chains saturated on the particle surface due to the presence of isobutyl group.
\end{abstract}

Keywords: POSS; dispersion; glass transition temperature; substituent chain lengths; agglomeration.

\section{INTRODUCTION}

The advancement made on the development of membranes for the separation of carbon dioxide $\left(\mathrm{CO}_{2}\right)$ from natural gas is still limited to the usage of polymeric membrane due to their good intrinsic properties [1-3]. However, they are subjected to the drawbacks of permeability and selectivity trade-off limitation as their polymer chain integrity is subdued by both physical aging and $\mathrm{CO}_{2}$ plasticization over time $[4,5]$. On the contrary, the resistance of inorganic membrane to the aforementioned conditions has contributed to its fragility and high manufacturing cost [1]. Therefore, recent developments are focused on the development of MMM which is made up of a polymeric phase with dispersed 
inorganic particles. A synergistic separation performance is thereby achieved as the polymeric phase provides superior permeability and processability whilst the dispersed inorganic phase provides a rigid frame suited for selective permeation of the desired gas $[6,7]$.

Polysulfone is usually chosen as the polymer matrix for the development of MMM due to its excellent thermal and chemical stability [8]. Attributed to its unique structure, the repeating phenylene rings provides a rigid backbone that is resistance towards molecule rotation and maintain molecule immobility. This aspect contributes to the polymer's high glass transition temperature at $190^{\circ} \mathrm{C}$ and mechanical strength $[9,10]$. Furthermore, observations of high resistance towards plasticization is made with PSf membrane whereby a good permselectivity of $\mathrm{CO}_{2} / \mathrm{CH}_{4}$ was maintained above an operating pressure of 30 bar $[11,12]$. Besides that, PSf is one of the common polymer matrix used for the separation of $\mathrm{CO}_{2}$ as it is absorbed preferentially into the polymer matrix compared to methane [13]. PSf are also commercially abundant and are known for its biocompatibility and ease of fabrication.

Current application of inorganic filler in MMMs can be categorized into conventional and unconventional filler. Conventional filler such as metal oxides, zeolites and carbon molecular sieves are porous in nature and they have been heavily researched on in the past decade due to the adaptability and versatility of their chemical composition [6]. Their incorporation induces molecular sieving effect in a membrane separating the gasses based on their shapes and sizes [14]. However, due to imperfect membrane morphology caused by the lack of interfacial interaction, industrial application of these conventional fillers is currently hampered. Consequently, researches have expanded towards the incorporation of unconventional fillers in MMMs.

Some of the unconventional fillers used in the development MMMs are metal organic framework, zeolite imidazolate framework, mesoporous silica, hollow zeolite spheres, layered silicate and more [15-18]. Amongst them, POSS possesses the most unique feature. It is a new class of organic/inorganic hybrid materials with a general formula of $\left[\mathrm{RSiO}_{3 / 2}\right]_{\mathrm{n}}$ with $n$ ranging from 6-12 and $R$ can be hydrogen, alkyl, olefin, alcohol, acid, amine, epoxy or sulfonate group. The chemical structure of POSS is shown in Figure 1. POSS hybrid material has a diameter that ranges from 1-3 nm [19]. The nano-size characteristics of POSS and its organic outer corner allows it to be easily dissolved into most organic solvent simplifying the process of MMMs fabrication. The organic substituents also provide better compatibility with polymer matrix with strong chemical and physical interactions [20]. Hence, the intrinsic mechanical and thermal properties of host polymer will not be compromised with the incorporation of POSS [1]. Besides, the smaller the particle size, the better the adhesion towards the polymeric matrix as it provides a larger interfacial area for bonding to occur [21]. Moreover, its ability to be functionalised into different variations has sparked an interest to develop MMMs with improved properties [22]. Most importantly, its separated, non-aggregated, well-defined size and structure induces good dispersion in various polymers [20, 23-25]

The incorporation of POSS in polymeric matrixes can be done via two approaches which are chemical cross-linking and physical blending. In chemical cross-linking, the formation of covalent bonds between POSS and polymer matrices are encouraged whilst in physical blending, POSS particles are embedded into the polymer matrices via melt mixing or solvent casting methods. Although chemical crosslinked POSS MMMs often leads to the development of a homogeneous membrane with no particle agglomerations, the development of POSS MMMs requires expensive synthetic procedures and long hour 
which decreases its commercialization ability [26]. Hence, physical blending method is explored due to its ease of processing, versatility and cost-effectiveness.

To the knowledge of the author, research available for physically blended POSS MMMs are limited to the application of molecular silica and multi-functional POSS. With the research available, it was shown that the addition of octaphenyl POSS (molecular silica) and octaaminophenyl POSS (multi-functional POSS) into polyimide matrix have led to the formation of phase separation with the former while exhibiting a homogenous morphology with the latter [27]. Another research showed that the addition of poly(ethylene glycol) (PEG) functionalized POSS (multi-functional POSS) in polymer intrinsic microporosity (PIMs) membrane had also led to the formation of phase separation [28]. Hence, amino functionalized POSS has been deemed to offer good compatibility with the polymer matrix. Herein, the motivation of this work is to study the effect of mono-functional PSOS with differing amine substituent chain lengths namely Aminopropylisobutyl POSS and Aminoethylaminopropylisobutyl POSS on polysulfone MMM in terms of its compatibility, dispersability and glass transition temperature,

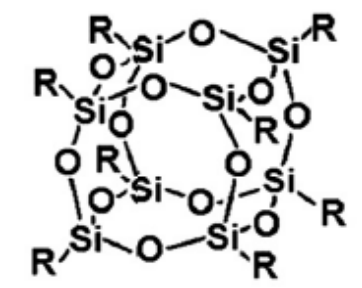

Figure 1. Chemical structure of POSS [29].

\section{METHODOLOGY}

\section{Materials}

Polysulfone (PSf) pellets (transparent) at $99 \%$ purity with an average molecular weight of 35000 and density of $1.24 \mathrm{~g} / \mathrm{ml}$ was purchased from Sigma Aldrich. AminopropylIsobutyl POSS and aminoethylaminopropylIsobutyl POSS at $97 \%$ purity were purchased from Hybrid Plastic. In this paper, aminopropylisobutyl will be abbreviated as (AMPOSS-a) and aminoethylaminopropyisobutyl will be abbreviated as (AMPOSS-b). The physical properties of POSS are given in Table 1. The chemical structure of AMPOSS-a and AMPOSS-b are shown in Figure 2. Solvent used for the development of MMMs is Tetrahydrofuran (THF) purchased from Merck with a purity of $99.8 \%$, a density of $0.889 \mathrm{~g} / \mathrm{ml}$ and boiling point between $65^{\circ} \mathrm{C}-67^{\circ} \mathrm{C}$.

Table 1: Physical properties of AMPOSS-a and AMPOSS-b

\begin{tabular}{|c|c|c|c|}
\hline Type of POSS & $\begin{array}{l}\text { Density } \\
\left(\mathrm{g} / \mathrm{cm}^{3}\right)\end{array}$ & $\begin{array}{l}\text { Refractive } \\
\text { Index }\end{array}$ & Solvent Solubility \\
\hline $\begin{array}{c}\text { Aminopropyl-isob } \\
\text { utyl }\end{array}$ & 1.13 & 1.49 & $\begin{array}{l}\text { Tetrahydrofuran, } \\
\text { chloroform, hexane }\end{array}$ \\
\hline $\begin{array}{l}\text { Aminoethylamino- } \\
\text { propylisobutyl }\end{array}$ & 1.17 & 1.50 & $\begin{array}{l}\text { Tetrahydrofuran, } \\
\text { chloroform }\end{array}$ \\
\hline
\end{tabular}




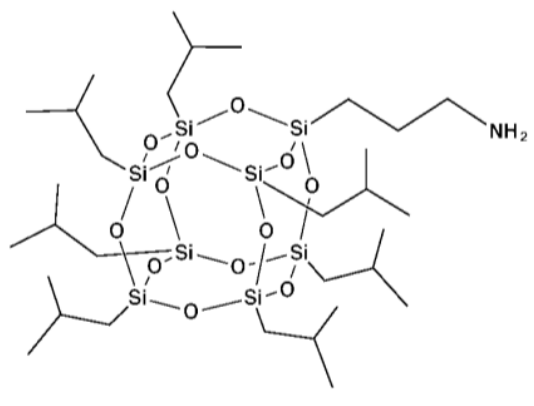

(a)

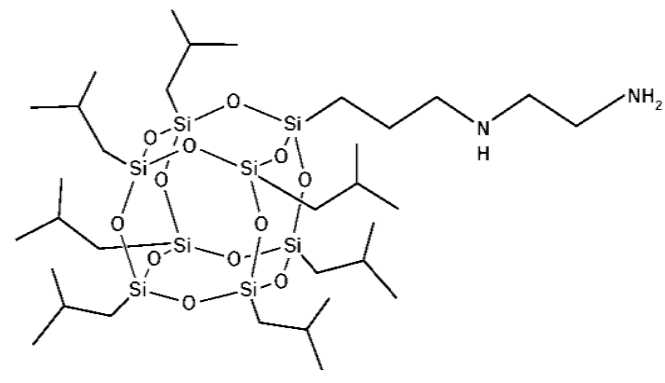

(b)

Figure 2. (a) Chemical structure of AminopropylIsobutyl (AMPOSS-a) POSS and (b) AminoethylaminopropylIsobutyl (AMPOSS-b) [29].

\section{Membrane Preparation}

$1 \mathrm{wt} \%, 2 \mathrm{wt} \%$ and $3 \mathrm{wt} \%$ of AMPOSS-a and AMPOSS-b were added into THF solvent and the solutions were placed into ultrasonic bath for $30 \mathrm{~min}$ for particle dispersion. PSf pellets were dried at $110^{\circ} \mathrm{C}$ for 24 hours before being added into the solution in batches. The dope solution was stirred at $400 \mathrm{rpm}$ until the PSfs were fully dissolved. The stirring speed was then dropped to $200 \mathrm{rpm}$ and stirred for another 8 hours. The dope solution was placed in an ultrasonicator to degas for $30 \mathrm{~min}$. The membrane was casted via dry phase technique on a thoroughly cleaned glass plate $(20 \mathrm{~cm} \times 25 \mathrm{~cm})$ with a $200 \mu \mathrm{m}$ casting knife $(8 \mathrm{~cm} \times 2 \mathrm{~cm} \times 2 \mathrm{~cm})$. The casted membranes $(23 \mathrm{~cm} \times 8 \mathrm{~cm})$ are left at room temperature for 24 hours and dried in a vacuum oven at $70^{\circ} \mathrm{C}$ for 3 hours to remove residual solvent. Schematics of the fabrication process is detailed in Figure 3.

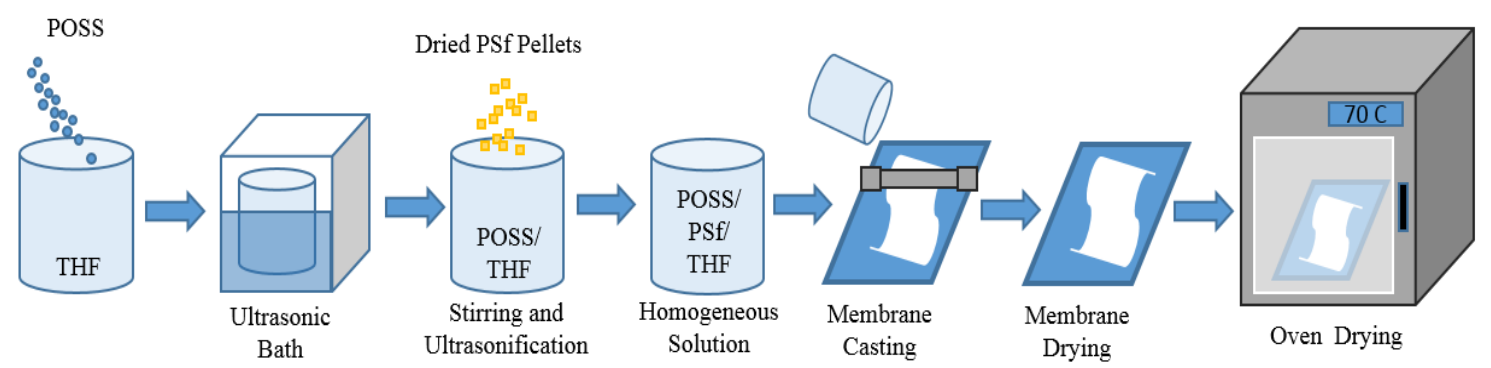

Figure 3. Schematics of POSS MMMs fabrication process.

\section{MEMBRANE CHARACTERIZATION}

\section{Membrane Morphology and Particle Dispersibility Study}

The membrane morphology was determined by using scanning electron microscope (SEM). Membrane morphology observed will help determine the compatibility between fillers and polymer as well as their dispersibility. Hence, the surface and cross-sectional morphologies of $1 \mathrm{wt} \%, 2 \mathrm{wt} \%$ and $3 \mathrm{wt} \%$ of AMPOSS-a and AMPOSS-b in PSf matrix were observed by SEM (Hitachi T3030). Samples were freeze-fractured in liquid nitrogen, coated with platinum and viewed under operating acceleration voltage of $15 \mathrm{kV}$. To further analyse the presence of the inorganic fillers incorporated and their dispersiblity, EDX analysis was employed using Bruker Quantax 70. 


\section{Thermal Analysis}

Differential scanning colorimetry (DSC) (TA Instrument, Q2000) was used to study the glass transition temperature of the membranes developed with and without the incorporation of inorganic fillers. The glass transition temperature was determined by heating the membranes $(\leq 5 \mathrm{mg})$ which have been cut into squares $(0.5 \mathrm{~cm} \times 0.5 \mathrm{~cm})$ from $30{ }^{\circ} \mathrm{C}$ to $400{ }^{\circ} \mathrm{C}$ with $\mathrm{N}_{2}$ purging at a heating rate of $10^{\circ} \mathrm{C} / \mathrm{min}$. The data collected were subsequently interpreted using Universal Analysis 2000 provided by TA Instrument.

\section{RESULTS AND DISCUSSIONS}

\section{Membrane Morphological Study}

SEM was done to provide qualitative measures for the study of material compatibility and particle distribution within the membrane. Particle aggregates could be seen in all MMMs despite the different fillers that has been utilised. The presence of particle agglomerations is detrimental to the performance of the membrane in the separation of gases as it may lead to the formation of undesirable channels across the polymer increasing its gas permeability but not selectivity $[30,31]$. Also, mechanical strengths of the membrane may be compromised with the presence of agglomerations as it creates more stress convergent points subjected to external forces [32].

As observed in the MMMs incorporated with AMPOSS-a in Figure 4(a), (b) and (c), the size of these particle agglomerates increased significantly with the loadings. However, in the latter images, although the frequency of particle agglomerates increased with the loadings, the size differences were not as obvious. Despite the advantage of nano-sized filler having a larger surface area for interfacial adhesion, it was not evident in this study. However, the agglomerations of both AMPOSS-a and AMPOSS-b were the impact brought by interparticle forces such as van der Waals and electrostatic forces. The surfaces of smaller particles are saturated with a higher percentage of atoms, therefore increasing its surface energy. With the heightened interparticle forces and surface energy, the particles agglomerates to achieve equilibrium [33, 34]. Besides, the phenomenon can also be caused by the association of hydrocarbon chains saturated on the surface of the particle by Van der Waals' attraction force [35]. The association of hydrocarbon chain in POSS particles can be contributed by the isobutyl group located at the surface of POSS.

Particle dispersion in $1 \mathrm{wt} \%$ and $2 \mathrm{wt} \%$ particle loadings in MMMs tended to accumulate at the upper region of the membranes. This could be an attribute of the density difference between the inorganic fillers and the polymer matrix [6]. The density difference between AMPOSS-a, AMPOSS-b and PSf were apparent at $1.16 \mathrm{~g} / \mathrm{ml}, 1.17$ $\mathrm{g} / \mathrm{ml}$ and $1.24 \mathrm{~g} / \mathrm{ml}$ respectively providing substantial explanation to the phenomenon discussed. However, the particle distribution exhibited at $3 \mathrm{wt} \%$ loading is significant better compared to those at $1 \mathrm{wt} \%$ and $2 \mathrm{wt} \%$ loadings. The increased in particle saturation at higher loadings in the membrane which might have prompted the migration of the particles downward.

The membranes in Figure 4 were observed to be slightly porous in nature. However, the pores observed were the result of ellipsoidal inclusions. The formation of these ellipsoidal inclusions or oval shaped holes were located all over the cross sections of the AMPOSS-b/PSf MMMs. Similar findings have been reported and the cause was identified to be the poor miscibility between the fillers with the polymer matrix [24]. Furthermore, the empty voids visible in Figure 4 were perhaps the result of filler aggregates that have been detached from the polymer matrix during the breakage of sample for SEM analysis [36]. Similarly, ellipsoidal inclusions were highly visible at 
1wt\% AMPOSS-a/PSf MMM compared to the rest. As aforementioned, the size of aggregates of AMPOSS-a increases with the particle loadings. The increase in aggregate size may have contributed to a rougher filler surface making detachment from the membrane harder during membrane breaking [37]. With that being said, the apparent ease of aggregate detachment from the polymer indicated a poor adhesion between the particles and the polymer matrix. Based on the observations made, it can be concluded that AMPOSS-a exhibit a better compatibility with polymer matrix.

Additionally, AMPOSS-b exhibited a poorer adhesion to the polymer matrix compared to AMPOSS-a due to the highly visible void formation around the outer perimeter of the inorganic fillers. The visibility of voids on both inorganic fillers showed minimal reactivity between the polymer and inorganic fillers although both fillers are reactive in nature. such observations were in contrast with many researches carried out with reactive POSS showing the development of homogeneous membrane [38, 39]. This is best explained by the method of membrane fabrication in this research. Unlike most researches done via melt blending, copolymerization and cross-linking; physical blending of polymer and filler does not focus on prompting polymer-filler reaction [40, 41]. In addition to that, the interfacial adhesion of AMPOSS-a MMMs were observed to improve with increased loadings. The aforementioned theory on particle reaching an equilibrium in surface energy might have contributed to this outcome.

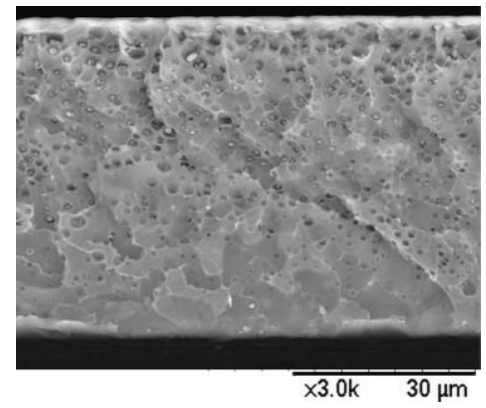

(a)

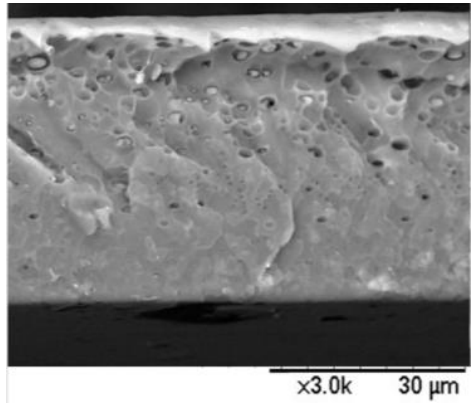

(d)

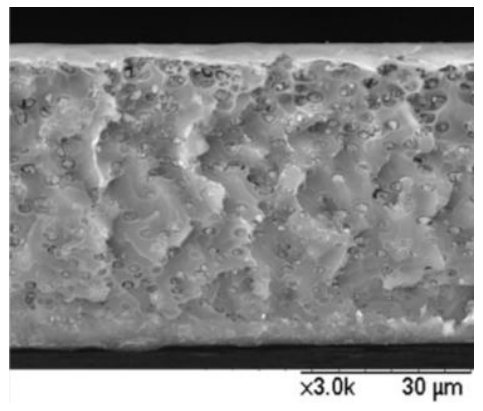

(b)

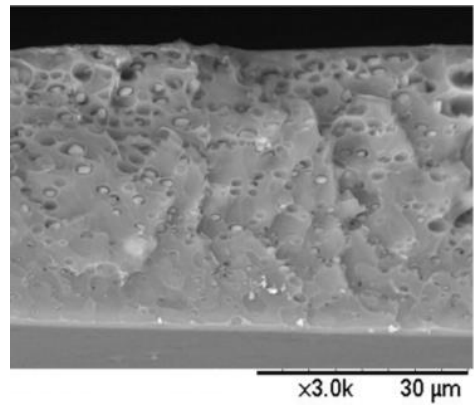

(e)

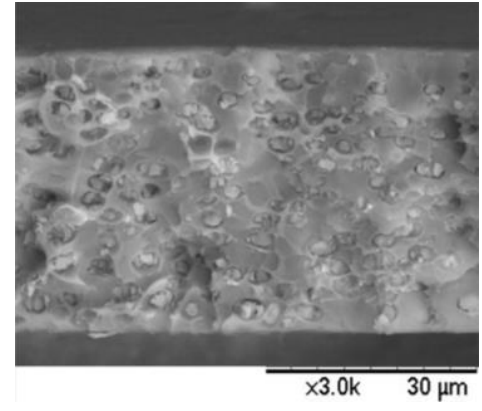

(c)

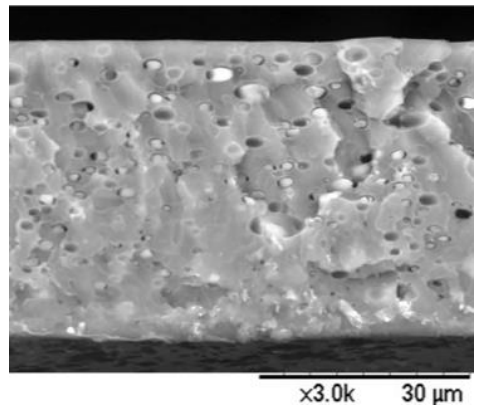

(f)

Figure 4. Cross sectional morphology MMMs with (a) $1 \mathrm{wt} \%$, (b) $2 \mathrm{wt} \%$, (c) $3 \mathrm{wt} \%$ AMPOSS-a and (d) $1 \mathrm{wt} \%$, (e) $2 \mathrm{wt} \%$ and (f) $3 \mathrm{wt} \%$ AMPOSS-b.

The observations made on the formation voided interphase, agglomerations and ellipsoidal inclusions showed a higher severity in AMPOSS-b MMMs Hence, the longer amine substituent chain length of AMPOSS-b POSS did not promote reactivity between polymer and filler. Nonetheless, the indifference observed in both inorganic fillers were 
identified to be contributed by POSS surface energy, which might be caused by the association of hydrocarbon chains saturated on the particle surface fur to the presence of isobutyl group.

\section{Particle Dispersion Study}

Figure 5 illustrated the cross-sectional mapping of silicon in MMMs for different loadings of AMPOSS-a and AMPOSS-b. Silicon was used as an indicator for the presence of the inorganic filler as it was unique only to the inorganic fillers added and it was represented by the blue specs on the dark background. Based on the distribution of silicon observed in MMMs with $1 \mathrm{wt} \%$ and $2 \mathrm{wt} \%$ AMPOSS-a, it is more homogeneous compared to others as there were no visible large accumulation of silicon. At $3 \mathrm{wt} \%$ AMPOSS-a, agglomerations were prominent, but the distribution of particles were still satisfactory. MMMs with AMPOSS-b exhibited particle agglomerations at loadings as low as $1 \mathrm{wt} \%$. Agglomeration sizes also increased with the loadings in contrast with the observation made in SEM analysis as large size agglomerations were not visible. EDX analysis was done to provide verifications to the observations made in SEM analysis and in the case of particle agglomeration sizes, SEM analysis has been proven otherwise. The cause of particle agglomerations had been discussed in membrane morphological study section. Furthermore, EDX analysis has also shown sparser particle distribution in the lower region of 1wt \% and 2wt\% of AMPOSS-a and AMPOSS-b MMMs which was in line with the results aforementioned in membrane morphological study section.

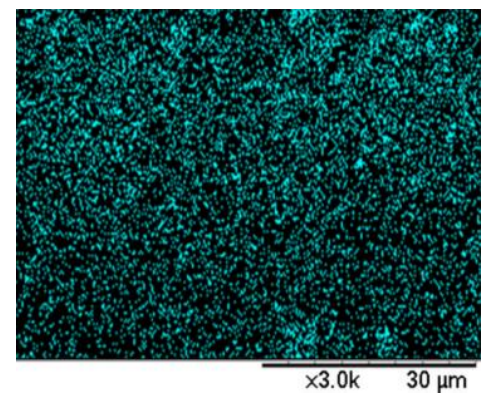

(a)

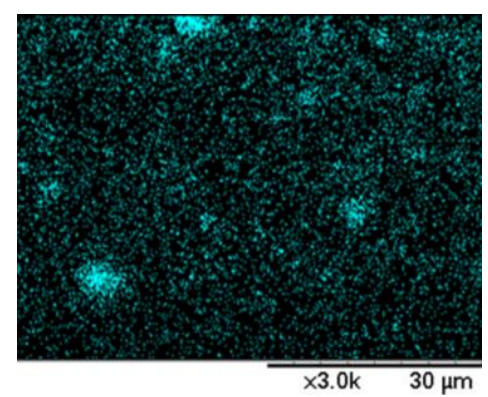

(d)

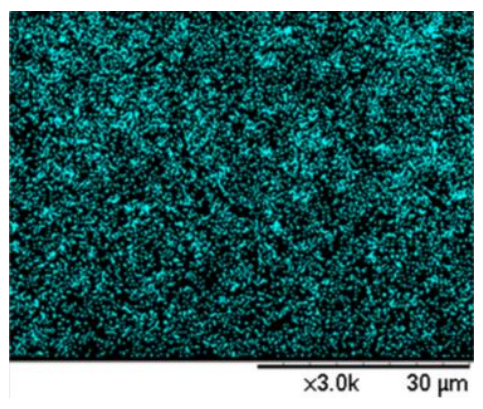

(b)

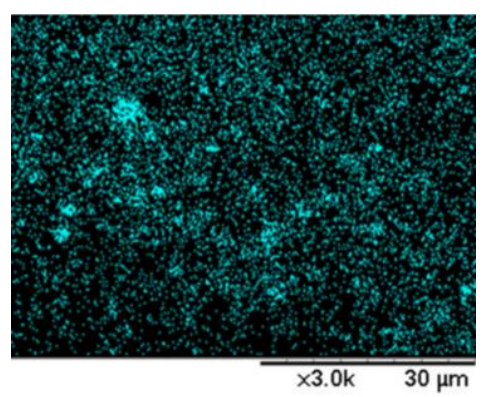

(e)

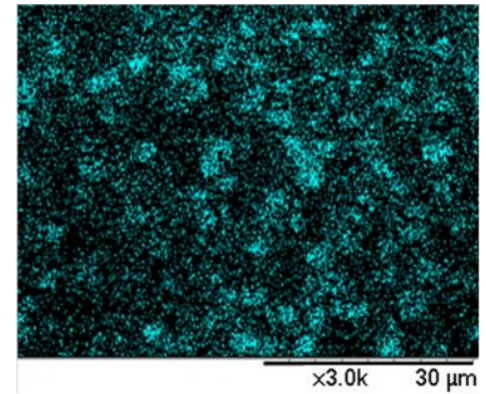

(c)

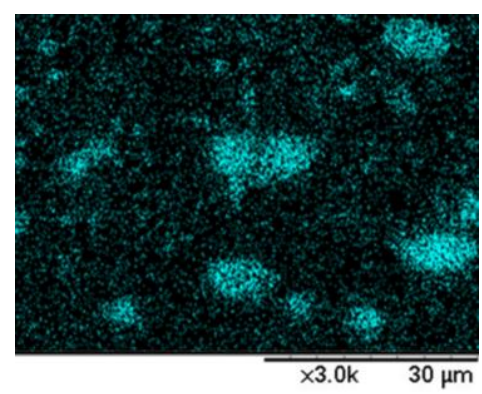

(f)

Figure 5. Cross section element mapping of MMMs with (a) $1 \mathrm{wt} \%$, (b) $2 \mathrm{wt} \%$, (c) 3 wt $\%$ AMPOSS-a and (d) $1 \mathrm{wt} \%$, (e) $2 \mathrm{wt} \%$, (f) $3 \mathrm{wt} \%$ AMPOSS-b. 


\section{Thermal Analysis}

DSC was used to determine the glass transition temperature $\left(T_{g}\right)$ of the membranes developed. The determination of $T_{g}$ enabled the distinction made between amorphous membrane and crystalline membrane. The term glass transition referred to the step like changes that occur in the membrane physical properties over a temperature interval [41]. The incorporation of POSS had different effects on membrane glass transition temperature as it was dependent on several key factors which included filler surface chemistry, amount and polymer-filler chain topology [26].

The overall $T_{g}$ of the MMMs were tabulated in Table 1. The glass transition of P-PSf was comparable to literatures found at $190^{\circ} \mathrm{C}$ [9]. The overall glass transition temperature of MMMs developed were significant lower compared to P-PSf. The overall decrement in $T_{g}$ could be attributed to the amount of POSS added. At low POSS loading $(<10 \mathrm{wt} \%)$, the nanoparticles acts as a plasticizer leading to flexible chains. On the contrary, at higher POSS loading, it may hinder the large scale segmental motion of the polymer chain. Similar behaviors have been observed elsewhere [42, 43].

In terms of surface chemistry, both inorganic fillers have heptaisobutyl structure. This structure was expected to increase the $T_{g}$ of MMMs due to its bulkiness which could inhibit local segmental motion of the polymer chains [44]. Besides, both inorganic fillers also possess one reactive vertex group. This was supposed to exhibit either a pendent or telechelic type topology by forming a bond with the neighboring polymer. Hence, bringing an increase in the membranes' glass transition temperature [41]. The inverse in the results obtained could only be explained by the increment of free volume induced by the agglomeration of particles and the increment in chain mobility caused by the incompatibility of materials which can be observed in Figure 4 [39]. The low $T_{g}$ might also be resulted by poorly dispersed inorganic fillers as a finely dispersed POSS might from a 3-D network that could result in a solid-like behavior [45].

Table 1. Glass transition temperature of MMMs developed.

\begin{tabular}{cc}
\hline Membrane & $T_{g}\left({ }^{\mathrm{C} C}\right)$ \\
\hline P-PSf & 194 \\
1AMPOSS-a/PSf & 147.8 \\
2AMPOSS-a/PSf & 146.9 \\
3AMPOSS-a/PSf & 146.9 \\
1AMPOSS-b/PSf & 149.9 \\
2AMPOSS-b/PSf & 150.2 \\
3AMPOSS-b/PSf & 153.7 \\
\hline
\end{tabular}

\section{CONCLUSIONS}

In conclusion, both mono-functional AMPOSS-a and AMPOSS-b exhibited poor compatibility and dispersion in the polymer matrix. However, it was evident that the increase in amine substituent chain lengths had a more adverse effect. Voided morphology and ellipsoidal inclusions observed in SEM appeared more prominently in AMPOSS-b MMMs, a result of material incompatibility. Particle dispersion were also poorer in AMPOSS-b MMMs accompanied by severe agglomerations of particles even at low particle loadings. The density difference between filler and polymer had also contributed to the uneven filler distribution with most filler found on the upper region of the membranes developed. Glass transition temperature of the MMMs as determined by 
DSC were found to be more amorphous than the pristine PSf membrane. The decrement in glass transition temperature were attributed to factors such as particle loadings, morphology and type of polymer-filler chain topology. The main reason identified for the results obtained in both SEM and DSC is the interparticle forces and particle surface energy. Therefore, future work can be done to alter the surface energy of the inorganic fillers via physical treatment such as the addition of suitable surfactant and in-situ polymerization. Additionally, the inorganic fillers can be further functionalised chemically coupling agent or undergo steric acid-treatment.

\section{ACKNOWLEDGEMENTS}

This research work was supported by Universiti Teknologi PETRONAS and YUTP-FRG Grant No. 0153AA-E08.

\section{REFERENCES}

[1] Rezakazemi M, Amooghin AE, Montazer-Rahmati MM, Ismail AF, and Matsuura T. State-of-the-art membrane based $\mathrm{CO}_{2}$ separation using mixed matrix membranes (MMMs): An overview on current status and future directions. Progress in Polymer Science 2014; 39(5): 817-861.

[2] Yampolskii Y. Polymeric gas separation membranes. Macromolecules 2012; 45(8): 3298-3311.

[3] Amooghin AE, Sanaeepur H, Pedram MZ, Omidkhah M, and Kargari A. New advances in polymeric membranes for $\mathrm{CO}_{2}$ separation. In: Mendez-Vilas A. and Solano-Martin A, editors. Polymer science: research advances, practical applications and educational aspect, ed Spain: Dormatex Research Center 2016, p 591.

[4] Robeson LM. The upper bound revisited. Journal of Membrane Science 2008; 320: 390-400.

[5] Baker RW and Lokhandwala K Natural Gas Processing with membranes: an overview. Industrial Chemical Engineering Research 2008; 47(7): 2109-2121.

[6] Goh P. S, Ismail A. F, Sanip S. M, Ng B. C, and Aziz M. Recent advances of inorganic fillers in mixed matrix membrane for gas separation. Separation and Purification Technology 2011; 81(3): 243-264.

[7] Bernardo EDP, Golemme G. Membrane gas separation: a review/state of the art. Industrial Chemical Engineering Research 2009; 48 (10): 4638-4663.

[8] Huang HL and Yang S. Filtration characteristics of polysulfone membrane filters. Journal of Aerosol Science 2006;37: 1198-1208.

[9] Sanders DF, Smith ZP, Guo R, Robeson LM, McGrath JE, Paul DR and et al. Energy-efficient polymeric gas separation membranes for a sustainable future: A review. Polymer. 2013;54: 4729-4761.

[10] Adewole JK, Ahmad AL, Ismail S, Leo CP, and Sultan AS. Comparative studies on the effects of casting solvent on physico-chemical and gas transport properties of dense polysulfone membrane used for $\mathrm{CO}_{2} / \mathrm{CH}_{4}$ separation. Journal of Applied Polymer Science. 2015;132: 42205.

[11] Bos A, Pünt IGM, Wessling M, and Strathmann H. $\mathrm{CO}_{2}$-induced plasticization phenomena in glassy polymers. Journal of Membrane Science. 1999;155: 67-78. 
[12] Ismail AF and Lorna W. Penetrant-induced plasticization phenomenon in glassy polymers for gas separation membrane. Separation and Purification Technology. 2002;27: 173-194.

[13] Mohamad MB, Fong YY, and Shariff A. Gas separation of carbon dioxide from methane using polysulfone membrane incorporated with zeolite-T. Procedia Engineering. 2016;148: 621-629.

[14] Bastani D, Esmaeili N, and Asadollahi M. Polymeric mixed matrix membranes containing zeolites as a filler for gas separation applications: A review. Journal of Industrial and Engineering Chemistry 2013; 19(2): 375-393.

[15] Adams R, Carson C, Ward J, Tannenbaum R, and Koros W. Metal organic framework mixed matrix membranes for gas separations. Microporous and Mesoporous Materials 2010; 13(6): 13-20.

[16] Weng TH, Tseng HH, and Wey MY. Fabrication and characterization of poly(phenylene oxide)/SBA-15/carbon molecule sieve multilayer mixed matrix membrane for gas separation. International Journal of Hydrogen Energy 2010; 35(13): 6971-6983

[17] Zornoza B, Esekhile O, Koros WJ, Tellez C, and Coronas J. Hollow silicate-1-sphere-polymer mixed matrix membrane for gas separation. Separation Purification Technology 2011; 77(1):137-145.

[18] Zornoza B, Irusta S, Tellez C, and Coronas J. Mesoporous silica sphere-polysulfone mixed matrix membrane for gas separation. Langmuir Article 2009; 25(10):5903-5909.

[19] Kuo S.W and Chang F.C. POSS related polymer nanocomposites. Progress in Polymer Science 2011; 36(12): 1649-1696.

[20] Dasgupta B, Sen S. K, and Banerjee S. Aminoethylaminopropylisobutyl POSS - polyimide nanocomposite membranes and their gas transport properties. Materials Science and Engineering: B 2010; vol. 168(1-3): 30-35.

[21] Chung T.S, Jiang L. Y, Li Y, and Kulprathipanja S. Mixed matrix membranes (MMMs) comprising organic polymers with dispersed inorganic fillers for gas separation. Progress in Polymer Science 2007; 32(4): 483-507.

[22] Rahman M. M, Filiz V, Khan M. M, Gacal B. N, and Abetz V. Functionalization of POSS nanoparticles and fabrication of block copolymer nanocomposite membranes for $\mathrm{CO}_{2}$ separation Reactive and Functional Polymers 2015; 86: $125-133$.

[23] Zhang W, and Müller AHE. Architecture, self-assembly and properties of well-defined hybrid polymers based on polyhedral oligomeric silsequioxane (POSS). Progress in Polymer Science 2013; 38:1121-1162.

[24] Rahman MM, Filiz V, Shishatskiy S, Abetz C, Neumann S, Bolmer S. PEBAX® with PEG functionalized POSS as nanocomposite membranes for $\mathrm{CO}_{2}$ separation. Journal of Membrane Science 2013; 437: 286-297.

[25] Li F, Li Y, Chung TS, and Kawi S. Facilitated transport by hybrid POSS®_ Matrimid ${ }^{\circledR}-\mathrm{Zn} 2+$ nanocomposite membranes for the separation of natural gas. Journal of Membrane Science 2010: 356: 14-21.

[26] Ayandele E, Sarkar B, and Alexandridis P. Polyhedral oligomeric silesqioxane (POSS)-containing polymer nanocomposites. Nanomaterials 2012;31: 445-475.

[27] Iyer P and Coleman MR. Thermal and mechanical properties of blended polyimide and amine-functionalized poly(orthosiloxane) composites. Journal of Applied Polymer Science 2008;108: 2691-2699 
[28] Yang L, Tian Z, Zhang X, Wu X, Wu Y, Wang Y and et al. Enhanced $\mathrm{CO}_{2}$ selectivities by incorporating $\mathrm{CO}_{2}$-philic PEG-POSS into polymers of intrinsic microporosity membrane. Journal of Membrane Science 2017;543: 69-78.

[29] Hybrid. Hybrid plastic. Retrieved from https://hybridplastics.com; 29 May 2017

[30] Adatoz E, Avci AK and Keskin S. Opportunities and challenges of MOF-based membranes in gas separations. Separation and Purification Technology 2015; $152 ; 207-237$.

[31] Mahajan R, Burns R, Schaeffer $M$ and Koros WJ. Challenges in forming successful mixed matrix membranes with rigid polymeric materials. Journal of Applied Polymer Science 2002; 86: 881-890.

[32] Zhang Y, Sunarso J, Liu S and Wang R. Current status and development of membranes for $\mathrm{CO} 2 / \mathrm{CH} 4$ separation: A review. International Journal of Greenhouse Gas Control 2013;12(1): 84-107.

[33] Jeon IY and Baek JB. Nanocomposites Derived from polymers and inorganic nanoparticles. Materials 2010; 3:3654-3674.

[34] Wu J and Mather PT. POSS Polymers: Physical properties and biomaterials applications. Polymer Reviews 2009; 49: 25-63.

[35] Wei D, Wei K, and Qiu J. Hydrophobic agglomeration and spherical agglomeration of wolframite fines. International Journal of Mineral Processing 1986;17: 261-271.

[36] Sánchez-Soto M, Schiraldi DA and Illescas S. Study of the morphology and properties of melt-mixed polycarbonate-POSS nanocomposites. European Polymer Journal 2009;45:341-352.

[37] Packham DE. Surface energy, surface topography and adhesion. International Journal of Adhesion and Adhesives 2003; 23:437-448.

[38] Monticelli O, Fina, A, Ullah A, and Waghmare P. Preparation, characterization, and properties of novel PSMA-POSS systems by reactive blending. Macromolecules 2009;42:6614-6623.

[39] Worthley CH, Constantopoulos KT, Ginic-Markovic M, Markovic E and Clarke SA. study into the effect of POSS nanoparticles on cellulose acetate membranes. Journal of Membrane Science 2013; 431:62-71.

[40] Cordes DB, Lickiss PD, and Rataboul F. Recent Developments in the chemistry of cubic polyhedral oligosilsesquioxane. Chemical 2010; 110(4): 2081-2173

[41] Raftopoulos KN and Pielichowski K. Segmental dynamics in hybrid polymer/POSS nanomaterials. Progress in Polymer Science 2016; 52:136-187.

[42] Ríos-Dominguez H, Ruiz-Treviño FA, Contreras-Reyes R, and González-Montiel A. Syntheses and evaluation of gas transport properties in polystyrene-POSS membranes. Journal of Membrane Science 2006; 271:94-100.

[43] Li Y and Chung TS. Molecular-level mixed matrix membranes comprising Pebax ${ }^{\circledR}$ and POSS for hydrogen purification via preferential $\mathrm{CO}_{2}$ removal. International Journal of Hydrogen Energy 2010; 35: 10560-10568.

[44] Bandyopadhyay P. and Banerjee S. Synthesis, Characterization and gas transport properties of polyamide-tethered polyhedral oligomeric silsesquioxane (POSS) Nanocomposites. Industrial \& Engineering Chemistry Research 2014; 53: 18273-18282.

[45] Joshi M, Butola BS, Simon G and Kukaleva N. Rheological and viscoelastic behavior of HDPE/Octamethyl-POSS nanocomposites. Macromolecules 2006; 39(5): 1839-1849. 